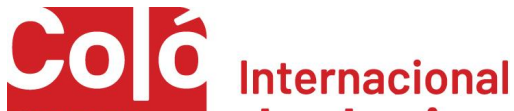 \\ guFd de design
}

\section{Flores do Morro: design para transformação social}

\author{
Glaucinei Rodrigues Corrêa; \\ Jéssica Kawaguiski Rodrigues; \\ Júlia Carvalho Passos
}

resumo:

Neste artigo, o objetivo é discutir a inovação social com base nas atividades do projeto de extensão "Flores do Morro: design, dança e arquitetura para o bem-estar social", da Universidade Federal de Minas Gerais com um grupo de mulheres da comunidade do Morro das Pedras - Belo Horizonte/MG. A proposta, nesse projeto, tem sido desenvolver com essas mulheres atividades para que possam enriquecer seus trabalhos artesanais, por meio da criatividade, da improvisação e da ludicidade. Os procedimentos metodológicos adotados no projeto valorizaram a relação construída entre os envolvidos no processo, bem como o reconhecimento dos saberes e das potencialidades de cada participante. Como principais resultados, pode-se destacar a melhora da autoestima das participantes, a interação dialógica entre a Universidade e a comunidade e, principalmente, o fortalecimento da identidade do grupo. Além disso, percebeu-se também o impacto social das ações do projeto, tanto em relação ao grupo de mulheres quanto a equipe envolvida.

\section{palavras-chave:}

Design; Design Colaborativo; Inovação Social; Interação Dialógica 


\section{Introdução}

De acordo com a Política Nacional de Extensão Universitária (FORPROEX, 2012, p. 16), a atividade de extensão "[...] é um processo interdisciplinar educativo, cultural, científico e político que promove a interação transformadora entre universidade e outros setores da sociedade." (grifos nossos). Para atingir essa transformação, um dos princípios fundantes é a Interação Dialógica, uma das cinco diretrizes que devem orientar a formulação, a implementação e o desenvolvimento de atividades de extensão ${ }^{1}$. De acordo com o FORPROEX (2012, p. 18), essa diretriz "orienta o desenvolvimento de relações entre Universidade e setores sociais marcadas pelo diálogo e troca de saberes, superando-se, assim, o discurso da hegemonia acadêmica." Ainda, segundo o documento, "para que a interação dialógica contribua nas direções indicadas é necessária a aplicação de metodologias que estimulem a participação e a democratização do conhecimento, colocando em relevo a contribuição de atores nãouniversitários em sua produção e difusão."

Além da Interação Dialógica, a Interdisciplinaridade também se torna importante para lidar com as questões complexas da sociedade, que necessitam, na maioria das vezes, de olhares múltiplos para serem solucionadas. Segundo o FORPROEX (2012, p. 18):

O suposto dessa diretriz é que a combinação de especialização e visão holista pode ser materializada pela interação de modelos, conceitos e metodologias oriundos de várias disciplinas e áreas do conhecimento, assim como pela construção de alianças intersetoriais, interorganizacionais e interprofissionais.

A partir dessas colocações pode-se questionar: Como estimular a participação e a democratização do conhecimento em projetos de extensão? E, também, como isso pode ser feito em projetos de extensão na área do design?

Por meio do design, em sua forma interdisciplinar, integrado a outros campos, como por exemplo da Arte e da Cultura, o projeto Flores do Morro: design, dança e arquitetura para o bem-estar social promove essa interação dialógica, bem como o fortalecimento da identidade de um grupo de mulheres do Morro das Pedras, região de vulnerabilidade social de Belo Horizonte e com baixo Índice de Desenvolvimento Humano (IDH). Esse grupo se configura como uma rede de apoio à medida que elas compartilham seus problemas, desafios, experiências e vivências pessoais. As atividades desse grupo iniciaram-se em 2011 e eram mantidas, até 2017, com verba pública municipal repassada ao Caritas Nossa Senhora de Fátima. No início, nos encontros do grupo no salão da igreja do bairro, eram realizadas oficinas artísticas (bordado, crochê e pintura) com a finalidade de promover a convivência através do artesanato e ações de assistência social. A partir de 2018, quando teve início este projeto, passaram a ter o apoio somente da Pró-Reitoria de Extensão da Universidade Federal de Minas Gerais (UFMG), por meio de pagamento de bolsas para as estudantes.

O projeto conta com dois professores coordenadores - um do curso de graduação em Design e outro do curso de graduação/licenciatura em Dança - quatro estudantes dos cursos de graduação da UFMG, sendo Teatro, Administração, Gestão Pública e Psicologia, e mais cinco profissionais: uma arquiteta, uma designer, duas dançarinas e uma professora de costura.

O projeto promove oficinas de estamparia, costura, criação de produtos e expressão em dança e teatro, de forma a integrar saberes manuais e corporais já existentes no grupo, como o bordado e o crochê. Além disso, busca-se desenvolver habilidades de gestão colaborativa, por meio do compartilhamento das tomadas de decisão que envolvem a concepção, a execução e a comercialização de produtos, bem como as tomadas de decisão que envolvem as criações em dança e teatro, em busca

\footnotetext{
${ }^{1}$ As outras diretrizes, segundo o FORPROEX (2012) são: Interdisciplinariedade e Interprofissionalidade, Indissociabilidade Ensino-Pesquisa-Extensão, Impacto na Formação do Estudante e, Impacto e Transformação Social.
} 
do equilíbrio entre desejos individuais e necessidades do coletivo e em busca da sustentabilidade do grupo, criado e organizado pela própria comunidade.

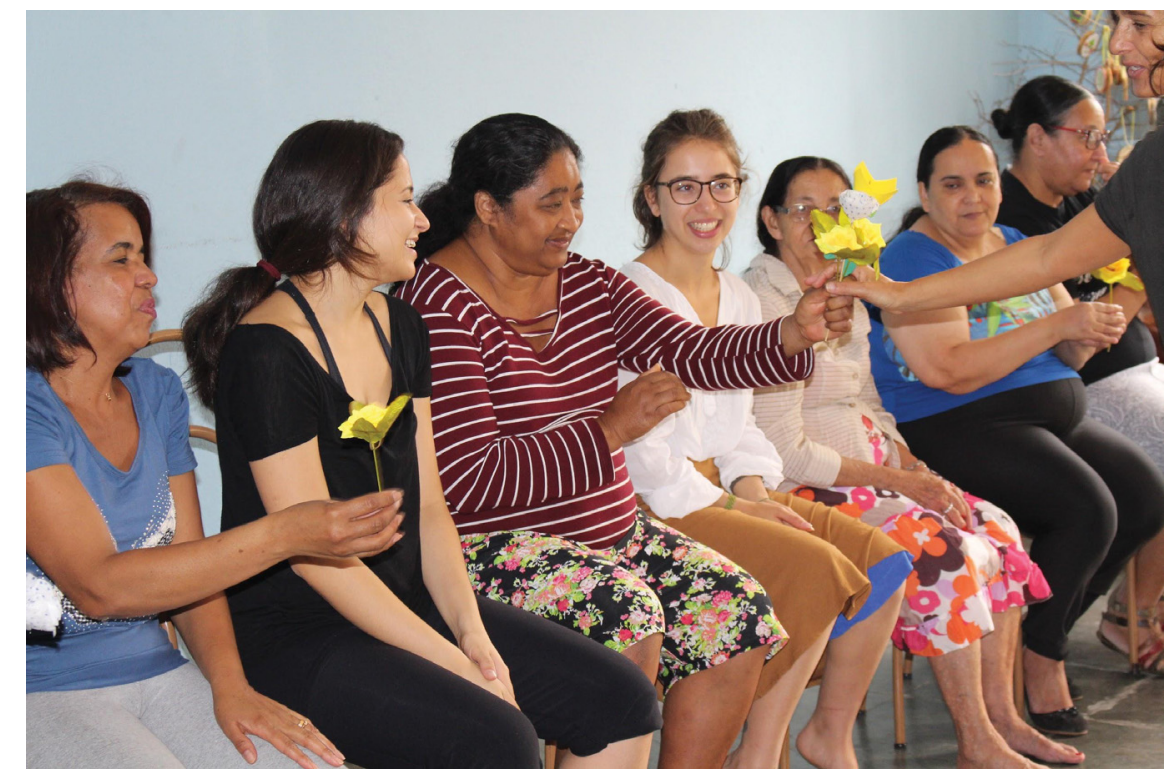

Fig. 1: Oficina de criação em dança. Fonte: acervo do projeto.

A criação artística coletiva é a base da atuação do projeto, na qual a memória, os fazeres tradicionais da comunidade, o autocuidado e o cuidado mútuo se cruzam para criar nossas formas de atuação. Os trabalhos privilegiam a utilização de recursos disponíveis à mão, como retalhos de tecido e resíduos, e priorizam a autoria coletiva, em função das particularidades do grupo. Portanto, percebese que o foco não está no produto, como resultado, mas no processo de criação, de caráter formativo, por estimular as mulheres participantes a se assumirem como sujeitos transformadores da realidade.

\section{Fundamentação teórica}

No Flores do Morro, três conceitos nos ajudam no entendimento e, principalmente, no aprofundamento das questões relacionadas à Interação Dialógica, que é um elemento fundante nos processos extensionistas. O primeiro é o de Aprendizagem Situada, de Jean Lave ${ }^{2}$. O segundo é um modo de pensamento do design, denominado de Reflexão-na-ação, por Donald Schon ${ }^{3}$. O terceiro é o conceito de Improviso, abordado por alguns autores, como Tim Ingold ${ }^{4}$ e Rodolfo Fuentes ${ }^{5}$. A proposta aqui é apresentar esses conceitos e mostrar como eles nos ajudam a estabelecer a troca de saberes com as nossas Flores ${ }^{6}$.

O conceito (ou teoria) da Aprendizagem Situada, de Jean Lave (1991), nos ajuda a entender melhor as relações sociais no cotidiano, a compreender os processos de aprendizagem e, por conseguinte, a relação dialógica com o grupo. Principalmente, por possibilitar um olhar de estranhamento para as práticas cotidianas, às quais estamos habituados a não perceber a aprendizagem, por isso, na maioria dos casos, a tratá-la como inexistente. Para Jean Lave a aprendizagem é parte da prática social e trata-se de um processo não explícito, um dos motivos que levam à ideia do dom, porque, geralmente, as atividades do dia-a-dia não são percebidas. A autora descreve a estrutura de organização da prática social cotidiana, que permite às pessoas se engajarem na prática e, nesse processo, como elas aprendem.

\footnotetext{
${ }^{2}$ Antropóloga social e teórica da aprendizagem social.

${ }^{3}$ Foi professor de estudos urbanos e educação no MIT (Instituto de Tecnologia de Massachusetts).

${ }^{4}$ Antropólogo britânico.

${ }^{5}$ Designer gráfico uruguaio.

${ }^{6}$ Nossas Flores são as mulheres que participam do projeto.
} 
Para a autora não há atividade que não seja situada: "Isso significa uma ênfase na compreensão abrangente que envolve a pessoa inteira, em atividade no e com o mundo; e ver que agente, atividade e mundo se constituem mutuamente, em vez de ver a pessoa como um corpo 'receptor' de conhecimento factual sobre o mundo."

Como nos mostra Jean Lave, as teorias da aprendizagem são, em sua maioria, sobre processos psicológicos dos indivíduos que levam à aquisição do conhecimento, tipicamente estruturados como “(1) transmissão (treino, ensino, inculcação), que leva para (2) entrada, estoque na memória, internalização do que é transmitido, seguindo-se para (3) transferência para a solução de problemas em novas situações" (tradução nossa).

Para traduzir um enfoque analítico específico sobre a aprendizagem, ela propôs o conceito de "Participação Periférica Legitimada" como um descritor do compromisso na prática social que vincula a aprendizagem como um constituinte integral. Segundo Lave (2011), "esse termo foi uma tentativa de propor um esquema analítico para descrever as práticas sociais cotidianas". Tentando explicar em outras palavras, para que o aprendizado aconteça deve haver participação, a qual tem vários modos e lugares de acontecer na prática. Ou seja, será periférica e tem de ser aceita pelos membros do grupo: legitimada. Para Lave, sempre quando pensamos na aprendizagem, a primeira coisa que cogitamos é a relação mestre-aprendiz ou professor-aluno. Mas, na prática, os papéis são surpreendentemente variáveis no tempo e no espaço, e a relação mestre-aprendiz não é uma característica definidora da aprendizagem.

E como esse conceito de Aprendizagem Situada nos ajuda a entender a interação dialógica? Por meio da aprendizagem, e não do ensino, é que se tem possibilidades de promover "a interação transformadora entre Universidade e outros setores da sociedade", bem como estabelecer a "troca de saberes entre as pessoas".

O segundo conceito, que na verdade é um modo de pensar do design, ou do pensamento de design, de quem faz e estuda design, é a Reflexão-na-ação, utilizado por Donald Schön (2000). Essa forma de fazer (e de agir) é inerente aos processos de design e pode contribuir com diversas áreas e processos pela riqueza de possibilidades de aplicação. O que Donald Schön vê na prática e no ensino do Design é que, por ter que lidar com problemas paradoxais, mal definidos e mal estruturados diariamente, os designers têm ferramentas tácitas e intuitivas de reflexão-na-ação (ou seja, diálogo com os objetos da situação enquanto ela ocorre) que são capacidades muito úteis para todos os profissionais. São habilidades desenvolvidas em momentos complexos, instáveis e conflituosos que acontecem ocasionalmente em qualquer prática, mas são lugar comum da atividade do Design.

Ter que lidar com a imprevisibilidade e a indeterminação é um dado inerente à maneira de pensar do designer e quando é parte da maneira de pensar de outros profissionais, faz com que eles se destaquem em meios onde normalmente há muitos métodos e teorias fechadas. De acordo com Schön (2000, p. 22) "há um núcleo central de talento artístico inerente à prática dos profissionais que reconhecemos como mais competentes [que] é um exercício de inteligência, uma forma de saber".

Sobre o ateliê de projetos, Schön (2000, p. 71) apresenta um diálogo de um professor com uma aluna ao longo do desenvolvimento de um projeto de arquitetura e analisa o que ele denomina de "reflexão-na-ação": refletir sobre a prática enquanto a realiza. Para ele, "o repensar leva a experimentos imediatos e a mais pensamentos que afetam o que fazemos". E segundo ele, é o que acontece durante o desenvolvimento do projeto de arquitetura e de design: o aluno é levado a refletir sobre suas decisões e atitudes e a modificá-las durante o processo.

Ao transpormos esse conceito para nossas ações e atividades de extensão, podemos fazer com que os envolvidos nos projetos (professores, estudantes e comunidade) possam lidar com esse modo de fazer (e de agir), de forma dialógica em suas ações e atividades por terem que tomar decisões baseados nas ações que estão acontecendo naquele momento. Num processo de interação, participação e troca de saberes.

O terceiro conceito, o Improviso, abordado em algumas áreas, como antropologia, dança e design, tem a ver com as surpresas, desafios e, claro, descobertas que acontecem durante o desenvolvimento de projetos, principalmente nos de extensão. Durante o desenvolvimento de projetos, os problemas aparecem e, às vezes (ou muitas vezes), mudam o rumo daquilo que havíamos planejado. E esse é o fascínio do trabalho que envolve o design: o acaso, o imprevisto elaborado, também presente em outras áreas, como na dança e no jazz. 
$\mathrm{O}$ acaso tem a ver com as soluções encontradas ao longo do caminho do desenvolvimento de um projeto. Essas soluções são frutos da experimentação. Quanto mais as pessoas experimentarem, mais chances terão de encontrar soluções criativas, inovadoras e, assim, obter as melhores descobertas.

Para Ingold (2012, p. 26), "improvisar é seguir os modos do mundo à medida que eles se desenrolam". Segundo ele, o pintor Paul Klee em seus cadernos, defendia, e demonstrava através de exemplos, que os processos de gênese e crescimento que produzem as formas que encontramos no mundo em que habitamos são mais importantes que as próprias formas. "A forma é o fim, a morte", escreveu ele; "o dar forma é movimento, ação. O dar forma é vida." Assim, como a planta cresce a partir de sua semente, a linha cresce a partir de um ponto que foi posto em movimento. Para o autor, "A vida está sempre em aberto: seu impulso não é alcançar um fim, mas continuar seguindo em frente". A planta, o músico ou o pintor, ao seguirem em frente, "arriscam uma improvisação".

Para Fuentes (2006), não podemos confundir improvisação com desordem. Improvisar, segundo esse autor, é escolher os conceitos e materiais específicos do projeto no qual se está trabalhando, identificados, analisados e pesquisados à exaustão. Para ele, o que o designer faz, assim como o músico de jazz, quando improvisa, é abrir sua paleta e escolher. Decidir quais de todos esses elementos vão participar dessa encomenda de trabalho, e de que maneira.

Esse improviso, de certo modo, permeia boa parte do desenvolvimento das atividades de extensão no Flores do Morro. Com a mente aberta, lidamos com o acaso e nos preparamos para ele. E qual a relação do Improviso com a Interação Dialógica?

É preciso estar aberto para as mudanças, para o improviso (elaborado), para o acaso, principalmente no que diz respeito às alterações que acontecem nos projetos e nas interações com os envolvidos em nossas atividades extensionistas. Esse conceito está diretamente relacionado com a participação das pessoas no processo e com a democratização do conhecimento, por colocar em relevo a "contribuição de atores não-universitários" para contribuírem nas soluções para os problemas que aparecem ao longo do desenvolvimento das atividades.

Esses três conceitos colocam em evidência o processo, o caminhar, o modo de fazer, e não o produto final. Nos três o mais importante é o caminho, o desenvolvimento, aquilo que foi e que está sendo vivido. Eles valorizam o percurso, e não o resultado em si. O resultado também é importante, mas para se alcançar a democratização do conhecimento, a troca de saberes e a participação, fundamental é dar ênfase ao modo como lidamos cotidianamente com as mulheres do Flores do Morro. Além disso, são importantes pela possibilidade de colaborar para a participação das nossas Flores ao colocá-las no epicentro das atividades. Esses conceitos podem ser utilizados juntos ou separadamente, e contribuem na medida em que nos fornecem meios para desenvolver, construir e, fundamentalmente, potencializar essa diretriz fundante para os projetos de extensão que é a Interação Dialógica.

\section{Design para a cidadania}

As atividades do Flores do Morro, antes do isolamento social, estavam acontecendo em encontros presenciais, realizados duas vezes por semana em um salão de uma igreja do bairro. Com duração aproximada de duas horas e meia, oficinas de criação e produção eram construídas pela nossa equipe junto às moradoras do bairro, de maneira a valorizar os saberes das participantes e a fazer dialogar esses saberes também com propostas trazidas pela equipe. As participantes, em sua maioria idosas, ressignificam as experiências das oficinas de diferentes formas, pontuando, por vezes, o seu papel educacional, a sua importância enquanto atividade social, o seu caráter de promoção do prazer e do bem-estar e também enquanto oportunidade de se cultivar a saúde.

A diversidade presente nessas oficinas, tanto no que se refere aos interesses das participantes quanto aos limites e potencialidades de cada sujeito, é tomada como ponto de partida para a elaboração das propostas. A valorização das singularidades de cada pessoa e também das especificidades de cada dia de encontro, demandam do coletivo um exercício insistente de escuta e readaptação das ideias que se organizam a priori.

São poucas as similaridades entre os trajetos de formação das pessoas que se encontram nessas oficinas, o que torna a comunicação de ideias também uma tarefa complexa de ser realizada. A comunicação no Flores do Morro acontece principalmente por vias sensoriais, através do toque, pela relação concreta com os objetos, pelo manuseio de materiais, pela percepção de formas, tamanhos e 


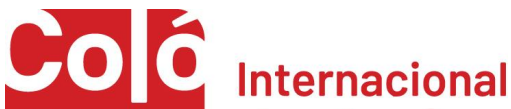 guro de design

texturas, pela abertura do estado de espírito às brincadeiras e as possibilidades de aproximação. Assim, são fatores fundamentais às experiências de compartilhamento do projeto a atenção ao momento presente e a disponibilidade para o encontro. É a partir do encontro que as demandas individuais e coletivas se enunciam, e que caminhos de desenvolvimento podem ser traçados.

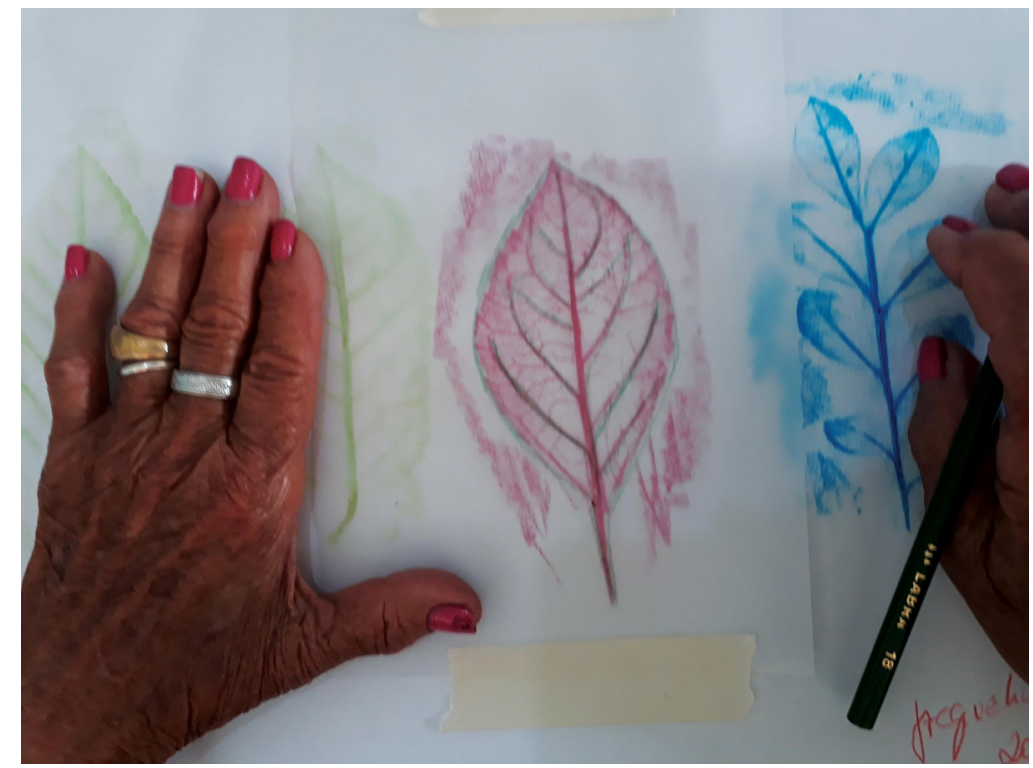

Fig. 2 - Oficina de desenho, como representar os veios e nervuras das plantas? Quais traços identificam e diferem uma folha da outra? Fonte: acervo do projeto.

Percebe-se que o design está presente não apenas na concepção dos produtos, mas se configura como a forma que lidamos com os desafios, a maneira como construímos os nossos caminhos, unindo senso crítico, para analisar as situações existentes; a criatividade para pensar outras situações possíveis, e o senso prático, para realizar nossos projetos, assim como aponta Manzini (2017). Portanto, o design passa a ser essa prática, esse modo de ser e fazer, necessários ao processo de inovação social, que tem a potência de apoiar mudanças sociais.

O design difuso, segundo a definição de Manzini (2017), aquele praticado por não profissionais da área, observado na organização desse grupo de convivência pela própria comunidade, conta com o apoio do design especializado, aquele realizado por profissionais, no desenvolvimento de produtos artesanais para a venda e geração de renda alternativa, dirigindo-se tanto para a resolução de problemas quanto para a produção de sentido. Na realidade, tanto o papel do designer, como dos outros profissionais e estudantes envolvidos passaram a ser de facilitar e potencializar processos existentes, a partir dos recursos disponíveis e das habilidades presentes. 


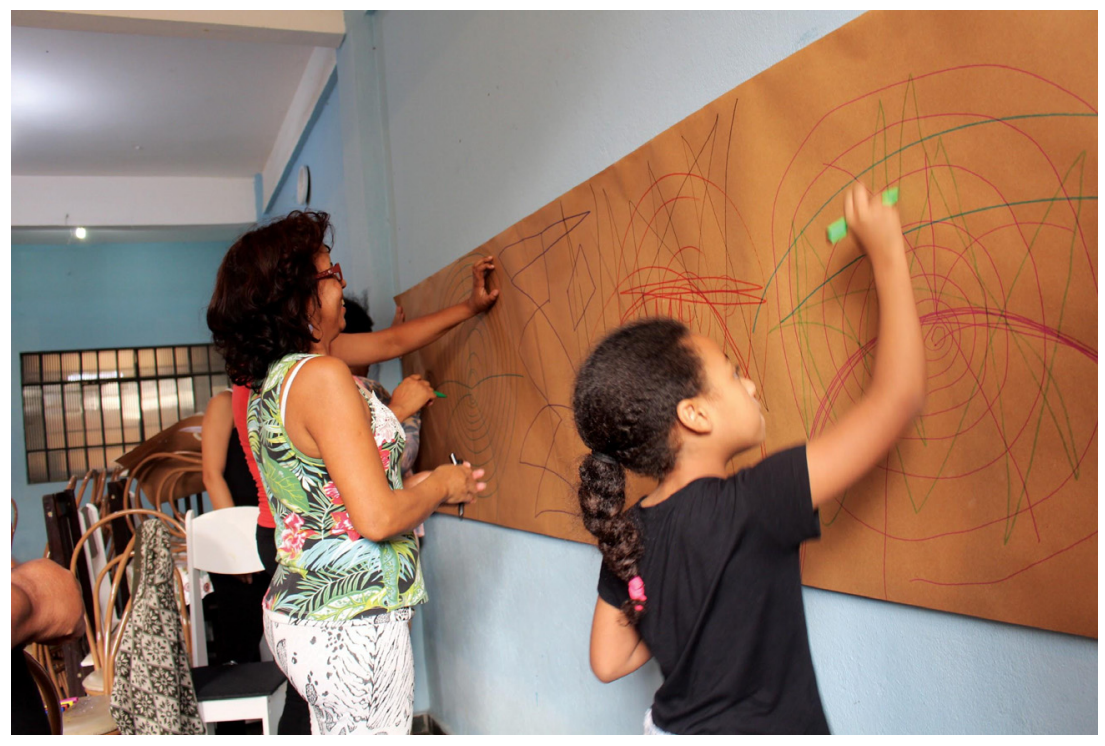

Fig. 3 - Oficina de formas e articulações, como o movimento do corpo influencia no traço. Fonte: acervo do projeto.

Um aspecto muito importante a ser destacado é a contribuição de todas as áreas que participam do projeto. Originalmente, foram as áreas do Design, da Dança e da Arquitetura, e mais recentemente, a partir do isolamento social, a adesão de mais quatro áreas: Teatro, Psicologia, Administração e Gestão pública. Isso demonstra a importância do conhecimento especializado para resolver os problemas da sociedade, como também a visão holística, fundamental para lidar com as questões complexas que esse tipo de relação universidade-comunidade apresenta.

Portanto, percebe-se o caráter de inovação social do projeto à medida em que ele aponta para novas formas de agir, resolver problemas e criar novas oportunidades, conduzidas por ações locais, não por mudanças externas institucionalizadas, ou seja, conduzidas por processos "de baixo para cima". De forma participativa e colaborativa, o grupo desenvolve oficinas e ações que promovem uma melhoria do bem-estar, através de uma ressignificação do trabalho e, dessa forma, vai em direção oposta aos padrões hegemônicos de produção e de consumo (Manzini, 2008).

O trabalho é ressignificado conforme incentiva as participantes a conduzirem ações carregadas de sentido, a partir do qual coloca-se em postura ativa para aprender, ensinar e criar novos caminhos viáveis, conforme aponta Manzini:

Estão também desafiando a ideia tradicional de trabalho, porque atribuem um valor muito maior ao trabalho manual e porque expandem a ideia de trabalho para uma gama mais ampla de atividades. Estas incluem tarefas que não são normalmente consideradas trabalho, tais como atividades de cuidado, gestão de bairros e formação de comunidades (MANZINI, 2017, p. 38).

Portanto, o design se apresenta como caminho para a viabilização de ideias comprometidas com a valorização do território, com o fortalecimento da identidade do grupo, com a promoção do bem-estar ativo ${ }^{7}$ e com a sustentabilidade de todo o processo. Por isso, entende-se a importância da cultura do cooperativismo, que valoriza recursos e saberes existentes no território, o que demanda dos mediadores sensibilidade para entender que a maneira de fazer também constrói um saber e precisa ser levada em conta no desenvolvimento da mediação. Dessa forma, passa-se a reconhecer, por exemplo, práticas da cultura popular, que tem muito a ensinar sobre métodos de aprendizagem criativa, sobre trabalho colaborativo e sobre o tempo lento, ou uma "ecologia dos tempos", que caracteriza o tempo

\footnotetext{
${ }^{7}$ Definição de Manzini, que define a condição na qual somos ativos, e que, sem esperar provocar grandes mudanças na esfera macro, conseguimos reorganizar o que já existe e produzir algo novo; temos liberdade de ação; somos construtores de nossos propósitos e inventores de novas realidades possíveis.
} 
necessário para se produzir algo, aproveitando ao máximo o processo e apreciando suas qualidades (MANZINI, 2017).

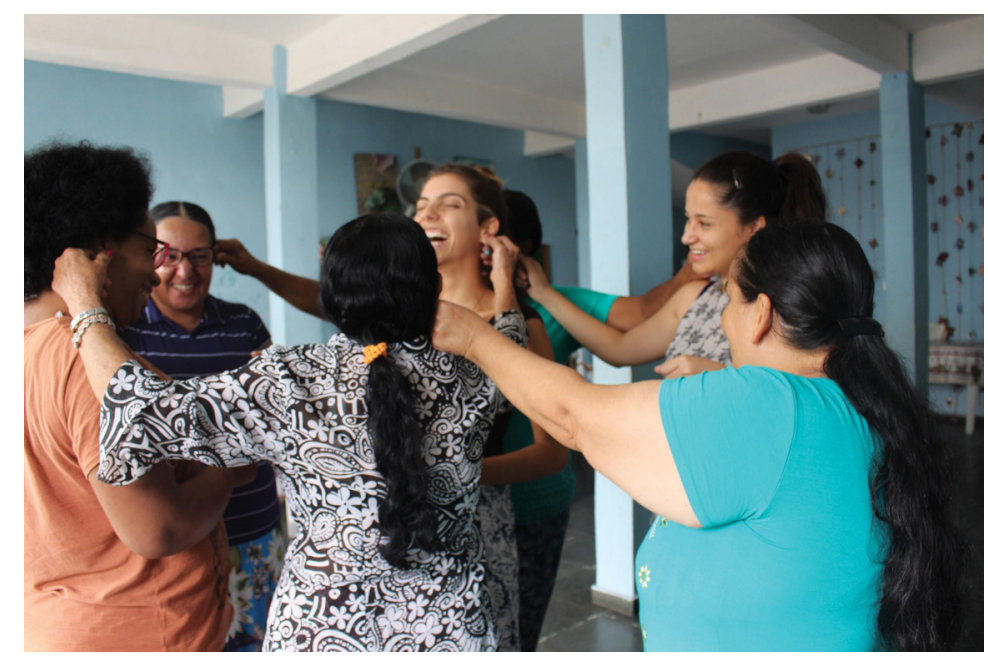

Fig. 4 - Oficina de brincadeiras da infância e da cultura popular. Fonte: acervo do projeto.

Os procedimentos metodológicos adotados no projeto valorizam a relação construída entre os envolvidos no processo, bem como o reconhecimento dos saberes e das potencialidades de cada participante. O desenvolvimento das atividades acontece de forma coletiva e rompe com a ideia tradicional de professor e aluno, conforme apontou Lave e Wenger (1991), proporcionando um aprendizado mútuo e enriquecedor tanto para as estudantes, ex-estudantes e professores quanto para o grupo de mulheres.

As atividades são divididas, em geral, em dois momentos: um momento processual, mais relacionado ao trabalho de base, de introdução. Nesta etapa trabalhamos conceitos de design, como cor, forma, composição e formas de reprodução, sem ter em mente um produto como objetivo. Isso permite uma maior aproximação da dança e do teatro, e esses conceitos podem ser trabalhados a partir do corpo no espaço, de forma mais abstrata, lúdica e espontânea. A segunda etapa é de elaboração de produtos, de aplicação dos conceitos trabalhados, na qual experimentamos muitos tipos de produtos para entender o que funciona melhor em um contexto de produção coletiva, em um grupo muito heterogêneo, e com limitações e habilidades diversas.

Atualmente, tivemos que adaptar estas etapas, percebendo esse período de isolamento social como uma grande fase processual, que está acontecendo de uma forma bem mais lenta, apesar dos meios digitais estarem mais presentes. Esse fato se dá pelo grupo não ter tanta familiaridade com aparatos tecnológicos e porque, como dito anteriormente, os encontros presenciais proporcionavam uma interação mais pessoal e dinâmica. Agora, a comunicação feita através de telas, muitas vezes não é direta, há desencontros de horários, problemas com os aparelhos ou sites, e nisso se passa bastante tempo. As manualidades tradicionais, diferentes do meio digital, muitas vezes se encaixavam de uma forma mais orgânica. Por exemplo, no caso de uma participante ensinando à outra um ponto de bordado, fica nítido como estar longe fisicamente, se torna um fator dificultante. Vislumbramos que agora, no segundo semestre de 2020, poderemos traçar caminhos possíveis para criação e elaboração de outros produtos, levando em conta que a experiência e a experimentação nesse contexto, também terá que ser adaptada, conduzida de forma mais lenta e gradual.

\section{Adaptação durante o isolamento social}

Nossas atividades presenciais foram suspensas na terceira semana de março, bem no início do isolamento social, já que muitas das nossas participantes são idosas e se encaixam no grupo de risco. Não sabíamos como seriam as atividades nos meses seguintes, e principalmente, como manteríamos 
contato com essas mulheres à distância, tendo em vista que várias não tinham acesso aos meios de comunicação. $\mathrm{O}$ acesso das mulheres a esses meios de comunicação tem sido uma das nossas maiores dificuldades, já que para o trabalho feito à distância, se faz necessário um mínimo de estrutura tecnológica, conhecimento e habilidade para manusear um aparelho telefônico, além de recursos necessários para realizar o contato.

Para criar uma perspectiva para nossas ações, pensando tanto na urgência do presente, como nas atividades a longo prazo, estamos tentando construir uma narrativa que seja esperançosa, em meio às invisibilidades do cotidiano. Muitas das dificuldades enfrentadas pelas mulheres, sempre estiveram presentes, e mais do que nunca, agora estão latejantes, nesse contexto em que a grande maioria do grupo é formada por mulheres negras, moradoras de periferias, que tem, frequentemente, os filhos e netos para criar, ou que não tiveram um estudo formal, e consequentemente encontram problemas para ter um trabalho com carteira assinada e uma renda fixa. Assim, nossa rede de apoio se fortalece à medida que construímos junto das participantes, a prioridade de nossas demandas. A criação de um financiamento coletivo online foi uma dessas alternativas que encontramos para auxiliar financeiramente as participantes, para que elas possam enfrentar esse momento de isolamento.

Apostamos também, como geração de renda alternativa para esse período, na fabricação de máscaras de proteção contra a COVID-19 e estamos recebendo encomendas de pessoas e de empresas, além de estarmos vendendo através das redes sociais. A mediação e a assessoria estão sendo feita à distância pela professora de costura do grupo. A intenção é manter o trabalho colaborativo e as etapas de estamparia, bordado e costura das máscaras são divididas entre as participantes, que costuram os produtos de suas residências.

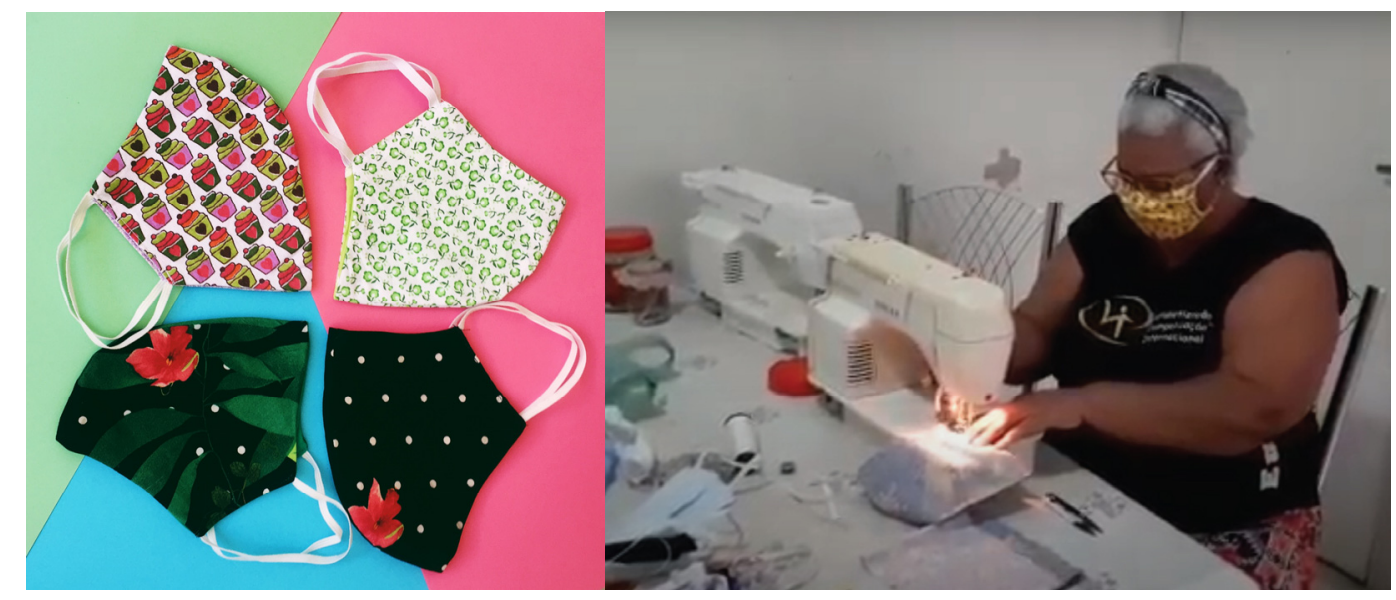

Fig. 5 - Confecção de máscaras por uma de nossas participantes, Terezinha Pereira. Fonte: acervo do projeto.

Além disso, distribuímos kits de bordado, estêncil e crochê, para que as participantes continuem os trabalhos em casa, já que muitas trouxeram questões sobre a falta de atividades durante o isolamento e o fato de ficarem muito sozinhas. Também por esses motivos, iniciamos uma parceria com psicólogos e psicanalistas voluntários para apoio psicológico virtual. Antes mesmo da pandemia, já percebíamos a importância de um acompanhamento psicológico para as participantes, o que se agravou com o isolamento social pela falta dos encontros e das trocas presenciais do grupo. Entendemos que o fato de os atendimentos precisarem ser virtuais pode ter facilitado essa parceria com os profissionais e pode viabilizar a continuidade do processo pós pandemia.

Portanto, estamos percebendo a importância das plataformas digitais nesse momento e estamos em um constante trabalho de inclusão digital das participantes. Recebemos doações de aparelhos celulares e realizamos algumas compras para que mais participantes pudessem acessar o apoio psicológico e pudessem estar em contato com o grupo. A cada semana, fazemos ligações por vídeo (via whatsapp, googlemeet ou jitsi), às vezes em grupo, para que elas também possam se encontrar virtualmente e estamos percebendo uma abertura crescente para os meios digitais, algo que era frequentemente recusado. 


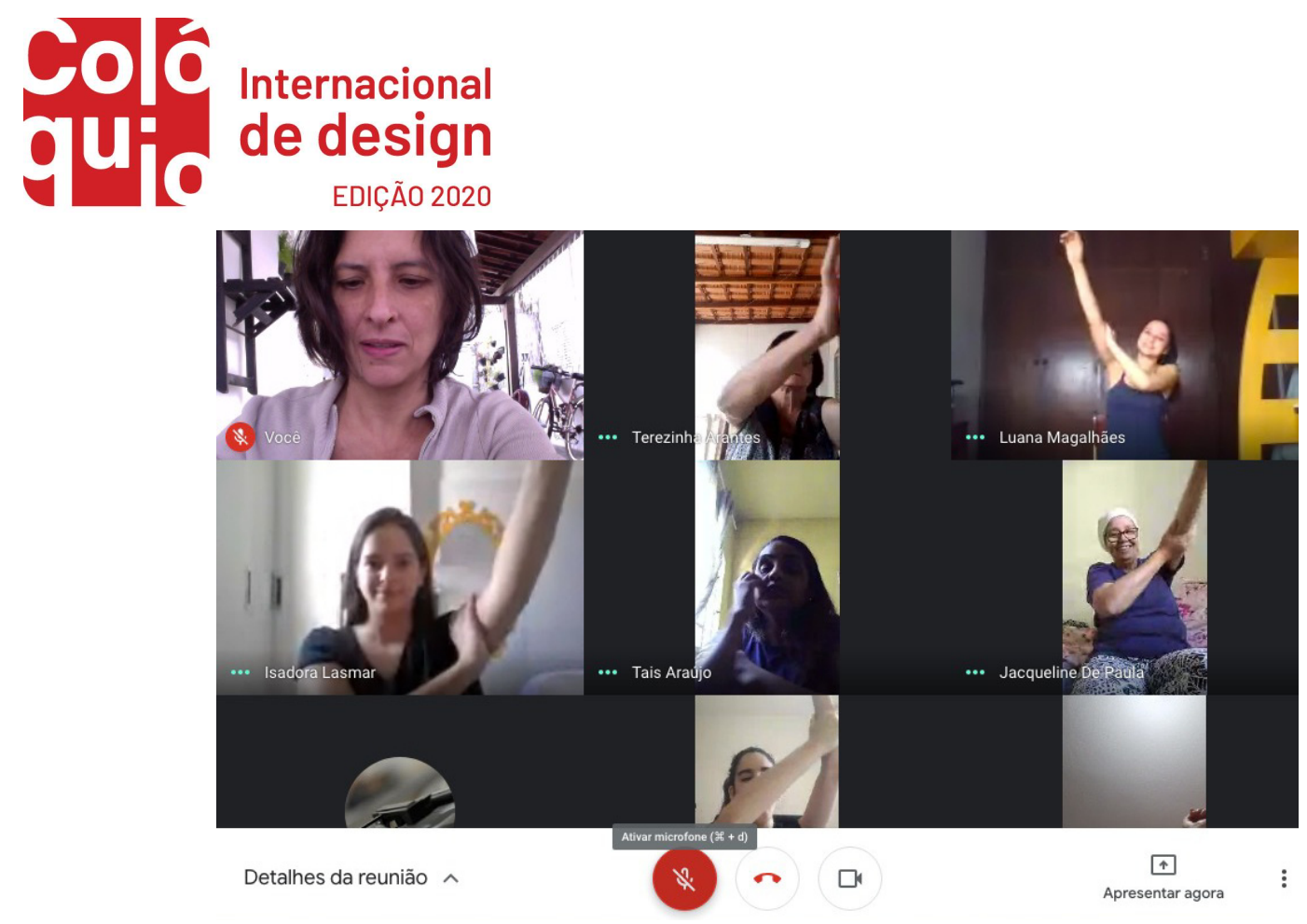

Fig. 6 - Oficina de exercícios corporais/cênicas. Fonte: acervo do projeto.

Ainda com relação aos meios digitais, a comunicação do projeto está sendo feita através das redes sociais, principalmente via Instagram e Whatsapp, ferramentas que facilitam o compartilhamento de conteúdos informativos com as participantes e possibilita uma interação mais próxima com o público externo. Observamos que com o isolamento, o volume de imagens, links e textos que estavam sendo compartilhados online, aumentaram significamente, tornando o filtro ou seleção dessas informações cada vez mais difícil. Qual fonte seria confiável? Utilizamos das ferramentas de criação visual, para produzirmos peças gráficas objetivas, com menos texto e explorando bastante as ilustrações, tendo como fonte as recomendações da Organização Mundial de Saúde (OMS). Disparamos nas nossas redes, por exemplo, um e-flyer que ensinava como utilizar e higienizar as máscaras caseiras. Acreditamos que esse tipo de informação ser divulgada por nós, grupo que as mulheres confiam, se sentem parte, gera maior engajamento e confiança por parte delas. Produzimos também outras peças de comunicação, que diziam respeito a divulgação da nossa Vakinha, e da nossa conta digital para doações diretas, como também nos atentamos para manter o Instagram sempre ativo, como uma espécie de retorno e transparência para as pessoas que nos acompanham e contribuem conosco de alguma forma.

Aumentamos também nossa visibilidade, por meio de reportagens para jornais locais televisionados e para a TV UFMG. Algumas plataformas também facilitaram nossas vendas, como o Mapa das Máscaras ${ }^{8}$, ou nos conectaram com outros projetos e facilitaram doações, como a plataforma Periferia Viva ${ }^{9}$.

Por termos passado a acessar aspectos mais diversos nesse período, como o financeiro e a saúde mental, de forma mais direta, acabamos nos envolvendo mais com os familiares das participantes, que passaram a estar mais ativos no grupo e, alguns deles, já se posicionando como integrante do Flores do Morro. Por fim, com a diversificação das atividades durante a pandemia, também abrimos uma chamada aberta para voluntários estudantes da UFMG e integraram à equipe, uma estudante de psicologia, uma de gestão pública e outra de administração.

\footnotetext{
${ }^{8}$ Mapeamento de máscaras, para fortalecimento da economia local durante pandemia:

https://www.google.com/url?q=https://www.mapadasmascaras.com.br/listing/mascaras-tecido-duplo-algodaofeitas-pelas-mulheres-do-grupo-flores-domorro/\&sa=D\&ust=1597532619540000\&usg=AFQjCNFUMW23eC_JnpA02GWZFkNTIOKVvg

${ }^{9}$ Plataforma para conexões que visam impacto social, durante pandemia: http://periferiaviva.org.br/
} 


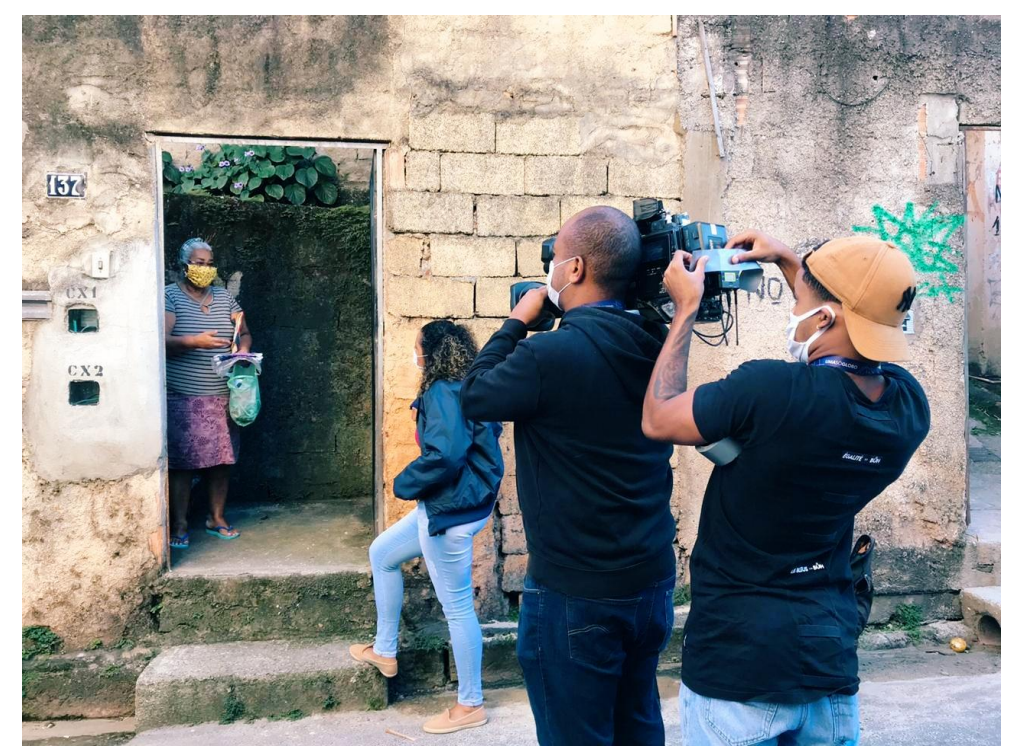

Fig. 7 - Entrevista para a Globo Minas - Plataforma Periferia Viva. Fonte: acervo do projeto.

Portanto, durante o período de isolamento social, aumentamos nossa articulação dentro e fora da comunidade, o que foi impulsionado também pela participação em um curso de mobilização social, que contou com a presença de diversos coletivos, grupos e lideranças do Morro das Pedras. Diversificamos nossas atividades e assim, buscamos formas de manter o grupo cada vez mais ativo e abrimos caminhos para novas ações, que têm potencial de continuidade pós pandemia.

\section{Considerações Finais}

Ao refletir sobre as atividades realizadas durante o projeto e o impacto das ações no grupo e na comunidade, remete-se ao papel da Universidade perante a sociedade. Conforme argumenta Corrêa (2017, p. 165), "por estarmos em uma instituição pública, temos o dever de dar algum tipo de retorno para a sociedade" e a realização dessa iniciativa é um exemplo, dentre tantos outros, do que podemos fazer.

Baseando-se nesse fato, alguns aspectos relacionados a esse projeto merecem ser refletidos. O primeiro deles tem relação direta com alguns dos resultados alcançados: desenvolver o sentimento de pertencimento do grupo e alcançar uma atitude de maior reconhecimento e valorização do próprio trabalho e de si mesma. Isso pode ser percebido através de relatos das participantes, dos processos coletivos de precificação dos produtos, do envolvimento crescente das pessoas nas atividades do dia a dia do projeto e de uma maior abertura para trocas e experimentações por parte das integrantes.

Essas transformações têm relação com as habilidades desenvolvidas, mas principalmente com o "estar e fazer junto". Mais do que "para quê" realizar tal trabalho, ou "o quê" será produzido, importa o "com quem" será feito e compartilhado. As participantes, em sua maioria, passaram a perceber a sua importância para o grupo, ao terem espaço de escuta e de fala e de entenderem que também podem ensinar umas às outras. Segundo Umbelina, participante do projeto "Não me falta nada, nem amizade, nem boa vontade, nem vontade de estar lutando com a gente. Se eu estiver contrariada, chego aqui e parece que meu coração vai abrindo."

Outro aspecto tem relação com a troca de saberes. Ou seja, tem relação com a interação dialógica entre a Universidade e a comunidade, como pode ser observado no documento de Política Nacional de Extensão Universitária (2012, p.p. 17-18), o qual "orienta o desenvolvimento de relações entre Universidade e setores sociais marcadas pelo diálogo e troca de saberes, superando-se, assim, o discurso da hegemonia acadêmica".

Ao vivenciar experiências como essa, fica evidente a importância que se deve dar aos saberes já existentes. Reconhecendo esse saber, é possível minimizar as relações de poder entre o meio 


\section{gog

acadêmico e a sociedade - sobretudo da classe socioeconômica baixa, como foi o caso desse projeto. Tudo isso remete ao cuidado com nosso fazer, uma ética de trabalho que culmina em um espaço de trocas e partilha. Assim, pode-se dizer que esse projeto tem sido um encontro de saberes para todos nós, encontro de indivíduos, com a própria vida, suas histórias, limites e capacidades. E, como em qualquer encontro, cada um traz e oferece ao outro o que tem. Aprendemos uns com os outros e continuamos a aprender.

Um terceiro aspecto tem relação com o processo de desenvolvimento desse projeto, que pode se tornar mais rico de possibilidades do que os próprios resultados. Ao se referir ao processo, está-se também dando destaque à riqueza das atividades realizadas, da integração entre as áreas, bem como ao empenho daquelas mulheres, que, apesar de todas as adversidades do cotidiano, levaram as atividades do projeto a sério, com empenho, dedicação e entusiasmo.

Esse projeto foi premiado na "Semana do Conhecimento 2018", da UFMG, como destaque na categoria "Trabalho". Essa premiação, além do reconhecimento do trabalho, ao levar muitas mulheres ao palco pela primeira vez, serviu como inspiração para a continuidade das atividades.

Para finalizar, pode-se afirmar que foram encontrados pontos de interferência e convergência entre todas as áreas de conhecimento envolvidas, o que permitiu somar os conhecimentos, nutrir as experiências coletivas em prol do grupo Flores do Morro e promover a inovação social.

Flores do Morro: design for social transformation

\section{Abstract:}

In this article the objective was to discuss social innovation based on the activities of the extension project "Flores do Morro: design, dance and architecture for social well-being", from the Federal University of Minas Gerais with a group of women from the Morro community das Pedras - Belo Horizonte / MG. The proposal, in this project, has been to develop activities with these women so that they can enrich their craft work, through creativity, improvisation and playfulness. The methodological procedures adopted in the project valued the relationship built between those involved in the process, as well as the recognition of the knowledge and potential of each participant. As main results, it can be highlighted the improvement of the participants' self-esteem, the dialogical interaction between the University and the community and, mainly, the strengthening of the group's identity. In addition, the social impact of the project's actions was also perceived, both in relation to the group of women and the team involved.

Keywords:

Collaborative Design; Design; Dialogic Interaction; Social Innovation

\section{Referências bibliográficas}

CORRÊA, Glaucinei Rodrigues (Org.). Catadores de sonhos: design em projetos de extensão. Escola de Arquitetura da UFMG. Belo Horizonte: 2017.

FORPROEX. Política Nacional de Extensão Universitária. Manaus-AM (2012). Recuperado em 7 de fevereiro, 2018, de https://www.ufmg.br/proex/renex/images/documentos/Pol\%C3\%ADticaNacional-de-Extens\%C3\%A3o-Universit\%C3\%A1ria-e-book.pdf.

FUENTES, Rodolfo. A prática do design gráfico: uma metodologia criativa. Oswaldo Antônio Rosiano (Trad.). Edições Rosari. São Paulo: 2006. 


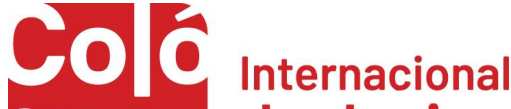 \\ gu. de design \\ EDIÇÃO 2020}

INGOLD, Tim. Trazendo as coisas de volta à vida: emaranhados criativos num mundo de materiais. Horizontes Antropológicos. Porto Alegre: 2012.

LAVE, Jean. Relato pessoal. In: Encontro Internacional de Linguagem, Cultura e Cognição, mar. 2011, Faculdade de Educação, Universidade Federal de Minas Gerais (UFMG).

LAVE, Jean. \& WENGER, Etienne. Situated learning: legitimate peripheral participation. Cambridge University Press. New York:1991.

MANZINI, Ezio. Design para a inovação social e sustentabilidade: comunidades criativas, organizações colaborativas e novas redes projetuais. Rio de janeiro: E-Papers, 2008.

MANZINI, Ezio. Design: Quando todos fazem design: uma introdução ao design para a inovação social/ Ezio Manzini; tradução Luzia Araújo. - São Leopoldo, RS: Ed. UNISINOS, 2017.

SCHÖN, Donald A. Educando o profissional reflexivo: um novo design para o ensino e a aprendizagem. Tradução de Roberto Cataldo Costa. Porto Alegre: Artes Médicas Sul, 2000. 